\title{
Significance of Differences Between Brain Temperature and Core Temperature (Delta T) During Mild Hypothermia in Patients With Diffuse Axonal Injury
}

\author{
Eiichi SueHIro, ${ }^{1}$ Hirosuke FUjISAwa,${ }^{1}$ Hiroyasu KoIZumi, ${ }^{1}$ Sadahiro NOMURA, ${ }^{1}$ \\ Koji KaJIWARA, ${ }^{1}$ Masami FUJII, ${ }^{1}$ and Michiyasu SUZUKI ${ }^{1}$
}

${ }^{1}$ Department of Neurosurgery, Yamaguchi University School of Medicine, Ube, Yamaguchi

\begin{abstract}
The differences between brain and bladder temperature (delta $\mathrm{T}$ ), and the relationship of delta $\mathrm{T}$ to cerebral perfusion pressure (CPP) and jugular venous oxygen saturation $\left(\mathrm{SjO}_{2}\right)$ were studied during hypothermia in 11 patients with severe traumatic brain injury, of whom 5 underwent conservative treatment for diffuse axonal injury (DAI) (DAI group) and 6 who underwent decompressive craniectomy for hematoma (SDH group). All patients underwent hypothermia treatment. Brain temperature was monitored via an intraparenchymal catheter. Bladder temperature was used as the core temperature. $\mathrm{SjO}_{2}$ was measured continuously. The outcome of all patients was evaluated at discharge using the Glasgow Outcome Scale. Delta $T$ in the SDH group was significantly lower than that in the DAI group. No relationship was found between delta $\mathrm{T}$ and $\mathrm{CPP}$ during the investigation period. A significant correlation between delta $\mathrm{T}$ and $\mathrm{SjO}_{2}$ was seen in the DAI group, but not in the $\mathrm{SDH}$ group. Decompressive craniectomy affects the brain temperature through external environmental factors. Measurement of brain temperature may be a reliable indicator of cerebral blood flow and brain metabolism in patients with DAI and closed cranium during hypothermia. Further experience is required to test this proposal.
\end{abstract}

Key words: brain temperature, cerebral perfusion pressure, decompressive craniectomy, jugular venous oxygen saturation, traumatic brain injury

\section{Introduction}

Hypothermia is known to provide neuroprotection after traumatic brain injury (TBI). ${ }^{4,10,15)}$ Therapeutic cooling of the brain prevents the release/diffusion of excitatory amino acids, ${ }^{2,19)}$ nitric oxide synthesis, ${ }^{14)}$ and disruption of the blood-brain barrier. ${ }^{16)}$ However, only body temperature measurement is not sufficient to infer the actual temperature of the brain under clinical conditions. ${ }^{11)}$ The brain temperature fluctuates under physiological and pathophysiological conditions, providing an indicator of changes in brain metabolism, cerebral blood flow (CBF), external environment, neuronal damage, and brain function. ${ }^{1,9)}$ Recently, technologies have been developed for measuring brain temperature directly, leading to a better understanding of the intracranial physiological state. Adequate brain temperature monitoring is also important for achieving efficient hypothermia. At present, jugular bulb temperature is used frequently for brain temperature monitoring, because of the ease of access. However, the various sites commonly used for temperature monitoring, such as the bladder, tympanic membrane, esophagus, pulmonary artery blood, and jugular bulb, may show discrepancies. ${ }^{7,18)}$ Recently, the significance of differences between brain temperature and core temperature (delta $\mathrm{T}$ ) has attracted attention. The brain temperature of patients with TBI can differ significantly from body temperature, ${ }^{20)}$ suggesting that this temperature difference might provide useful prognostic information. Furthermore, the difference between brain and rectal temperature is correlated with CBF and outcome. ${ }^{17)}$ Decompressive craniectomy is frequently performed for relief of medically refractory intracranial pressure (ICP) caused by severe brain edema, and has large effects on regional blood flow, metabolism, and heat ex-

Received January 18, 2011; Accepted June 1, 2011

Author's present address: E. Suehiro, MD, PhD, Department of Neurosurgery, Kenwakai Ohtemachi Hospital, Kitakyushu, Fukuoka, Japan. 
change. ${ }^{21)}$ Therefore, the effect of decompressive craniectomy must be considered in monitoring brain temperature.

The present study examined the difference between brain and bladder temperature, and the relationship to cerebral perfusion pressure (CPP) and jugular venous oxygen saturation $\left(\mathrm{SjO}_{2}\right)$ in patients undergoing hypothermic therapy with or without decompressive craniectomy.

\section{Materials and Methods}

Brain temperature monitoring was performed in 11 patients after severe TBI with a Glasgow Coma Scale (GCS) score of 8 or less on admission. The 10 male patients and one female patient were aged 15 to 73 years (mean 44.5 years). Five patients underwent conservative treatment for diffuse axonal injury (DAI). Six patients underwent decompressive craniectomy for evacuation of subdural hematoma (SDH) or contusional hematoma. The outcome of all patients was evaluated at discharge using the Glasgow Outcome Scale. All patients or family gave informed consent to the procedures.

Anesthesia was induced using midazolam $(0.2$ $\mathrm{mg} / \mathrm{kg}$ ). Muscle relaxation was achieved with vecuronium bromide $(0.1 \mathrm{mg} / \mathrm{kg})$. Anesthesia was maintained with midazolam $(0.2-0.4 \mathrm{mg} / \mathrm{kg} / \mathrm{hr})$, butorphanol tartrate infusion $(0.02-0.04 \mathrm{mg} / \mathrm{kg} / \mathrm{hr})$, and vecuronium bromide infusion $(0.05 \mathrm{mg} / \mathrm{kg} / \mathrm{hr})$ during hypothermia. After intubation, ventilation was mechanically controlled to maintain the $\mathrm{PaCO}_{2}$ within the range $30-35 \mathrm{mmHg}$. All patients received medical management to maintain the ICP below 20 $\mathrm{mmHg}$, and the mean CPP above $70 \mathrm{mmHg}$. If necessary, vasopressor agents such as dopamine were used to support blood pressure, or glycerol was used to reduce ICP.

All patients underwent hypothermia using watercooling blankets. The brain temperature was reduced to $33^{\circ} \mathrm{C}$ or $35^{\circ} \mathrm{C}$, then maintained at this level for at least 3 days, depending on the individual patient's ICP. After hypothermia, the patients were rewarmed slowly at a rate not exceeding $0.5^{\circ} \mathrm{C} /$ day.

An ICP sensor (Camino Laboratories, San Diego, California, USA) was carefully inserted into the brain tissue (right frontal lobe) to measure ICP and brain temperature. The probe was placed $2-2.5 \mathrm{~cm}$ from the brain surface, and the ICP and brain temperature were measured continuously. The accuracy of the temperature measurement was $\pm 0.3^{\circ} \mathrm{C}$. Using a retrograde internal jugular vein approach, a $5.5 \mathrm{Fr}$ Opticath (Dainabot, Tokyo) was inserted into the internal jugular vein via a $6 \mathrm{Fr}$ introducer sheath. The catheter was then advanced to the jugular bulb. The correct position of the catheter tip was checked radiologically. The $\mathrm{SjO}_{2}$ and the internal jugular vein blood temperature were measured continuously. $\mathrm{SjO}_{2}$ was corrected by measurement of blood sampled from the internal jugular vein at least once per day. Bladder temperature was measured continuously with a commercially available thermocouple (Terumo® ${ }^{\circledR}$, Tokyo) for core temperature. The accuracy of the temperature measurement was $\pm 0.3^{\circ} \mathrm{C}$ $\left(32-40^{\circ} \mathrm{C}\right)$. Water at $32^{\circ} \mathrm{C}$ or $35^{\circ} \mathrm{C}$ measured with a mercury thermometer was also found to be at the same temperature using the ICP sensor and the thermocouple for bladder temperature. The hemodynamic monitoring included continuous measurements of arterial blood pressure, heart rate, and peripheral oxygen saturation.

All clinical parameters, including arterial blood pressure, ICP, $\mathrm{SjO}_{2}$, brain temperature, and bladder temperature, were recorded every hour from all patients. These data were used as parameters every 8 hours during the hypothermic period when the brain temperature was below $36.0^{\circ} \mathrm{C}$. The patients were classified into two groups based on the therapeutic treatment given: DAI group, 5 patients with conservative treatment; SDH group, 6 patients with decompressive craniectomy.

In the first analysis, the temperature difference (delta $\mathrm{T}$ ) between the brain and bladder was used. Differences between the mean delta $\mathrm{T}$ in the DAI and SDH groups were examined with the unpaired $t$ test. In the second analysis, CPP was calculated with the mean arterial blood pressure and ICP. The correlation between delta $\mathrm{T}$ and $\mathrm{CPP}$ or $\mathrm{SjO}_{2}$ was studied with Pearson's linear regression method. Differences were considered statistically significant at $p$ $<0.05$.

\section{Results}

The mean delta $\mathrm{T}$ of all patients was $-0.17 \pm 0.02$ ${ }^{\circ} \mathrm{C}$ (mean \pm standard error of the mean). The mean delta $\mathrm{T}$ in the SDH group $(-0.23 \pm 0.03)$ was significantly lower than that in the DAI group $(-0.08$ $\pm 0.04)(p=0.0021)$. No relationship was found between delta $\mathrm{T}$ and CPP during the investigation period (Fig. 1). Figure 2 illustrates the relationship of delta $\mathrm{T}$ to $\mathrm{SjO}_{2}$. A significant correlation between delta $\mathrm{T}$ and $\mathrm{SjO}_{2}$ was seen in the DAI group $(\mathrm{R}=$ $0.438, \mathrm{p}=0.0004$ ). However, no such correlation was found in the SDH group. The clinical outcomes of patients in the DAI group were good recovery in 1 case, moderate disability in 2 , and persistent vegetative state in 2. The outcomes in the SDH group were moderate disability in 1 case, severe disability in 3, and persistent vegetative state in 2 . 

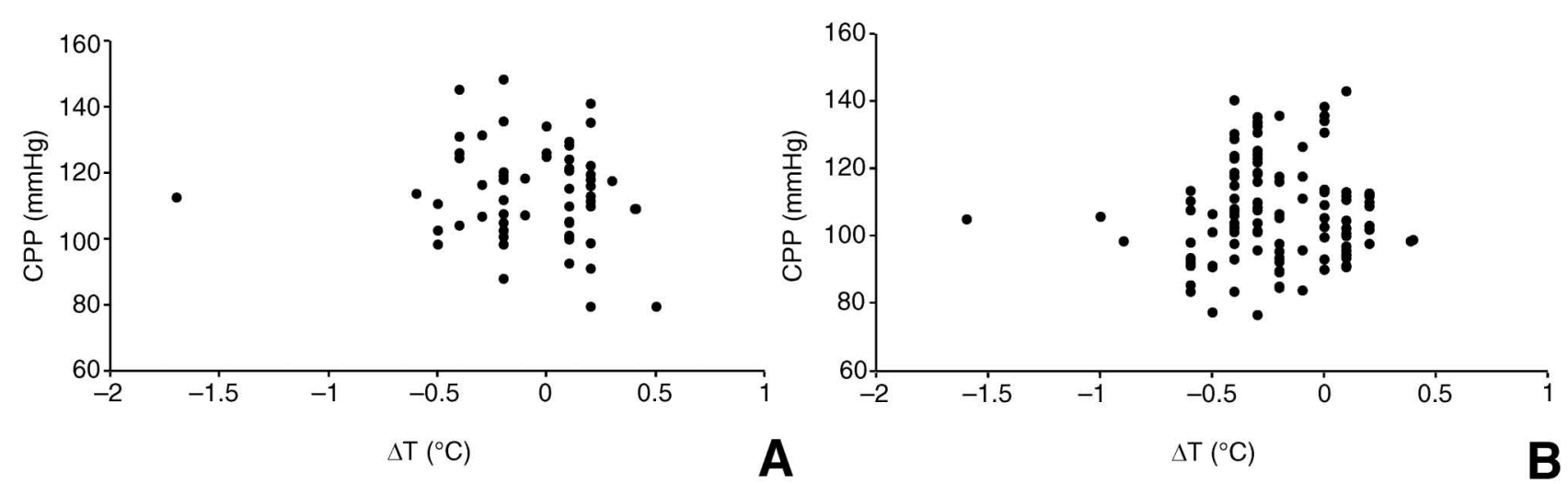

Fig. 1 Relationships between brain and bladder temperature difference (delta $\mathrm{T}$ ) and cerebral perfusion pressure (CPP) in 5 patients who underwent conservative treatment for diffuse axonal injury (DAI group, A) and 6 patients who underwent decompressive craniectomy for evacuation of subdural hematoma (SDH group, B).
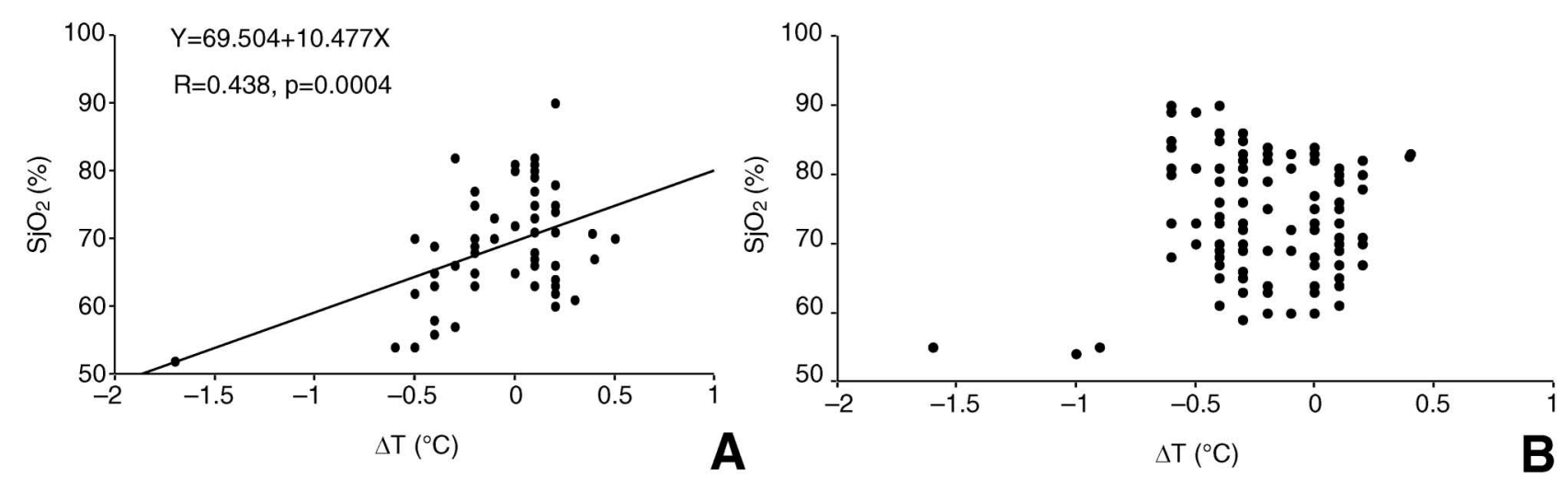

Fig. 2 Relationships between brain and bladder temperature difference (delta $\mathrm{T}$ ) and jugular venous oxygen saturation $\left(\mathrm{SjO}_{2}\right)$ in 5 patients who underwent conservative treatment for diffuse axonal injury (DAI group, A) and 6 patients who underwent decompressive craniectomy for evacuation of subdural hematoma (SDH group, B).

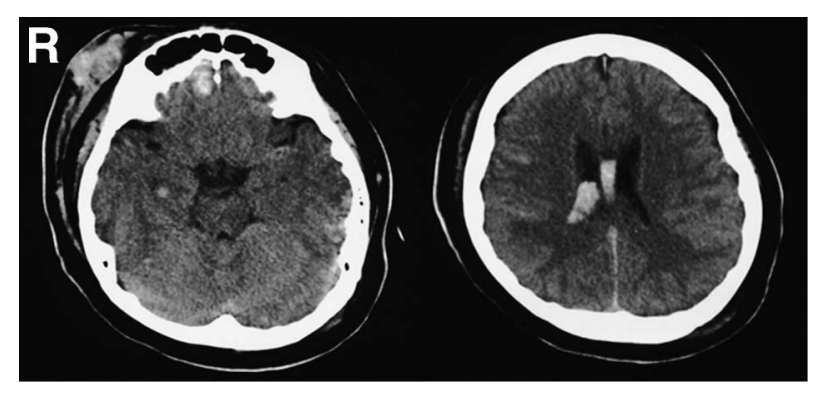

Fig. 3 Representative case. Computed tomography scans on admission showing intraventricular hemorrhage and contusion in the right frontal lobe.

\section{Representative Case}

A 17-year-old male was involved in a motor vehicle accident and was admitted to our hospital with dis- turbed consciousness of GCS score 6 (E1, V1, M4). Computed tomography showed intraventricular hemorrhage and a small contusion in the right frontal lobe (Fig. 3). He underwent conservative treatment with hypothermia therapy with neuromonitoring. On Day 4, ICP suddenly elevated and $\mathrm{SjO}_{2}$ decreased. At the same time, delta $\mathrm{T}$ gradually decreased (Fig. 4). After appropriate ICP treatment, $\mathrm{SjO}_{2}$ recovered. Correspondingly, delta $\mathrm{T}$ also increased (Fig. 4).

\section{Discussion}

Increasing amounts of evidence indicate that brain temperature is higher than core temperature in patients with acute neurological injuries. However, brain temperature was lower than bladder temperature in most of our patients. This study measured brain temperature with intraparenchymal catheters 

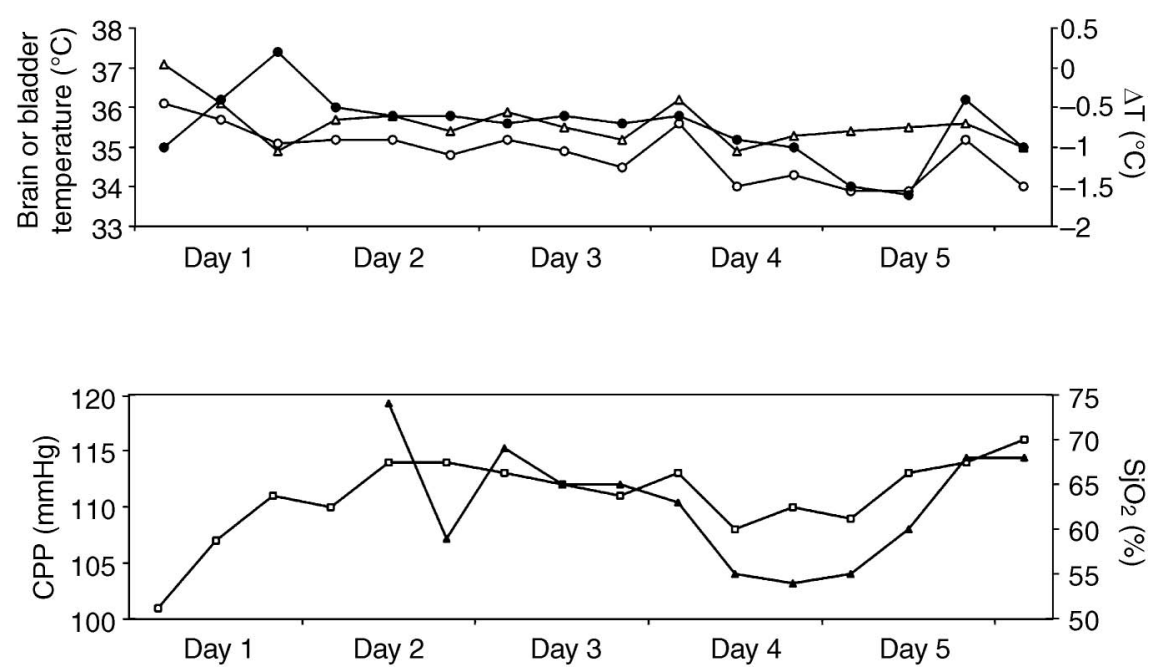

Fig. 4 Representative case. Graph showing changes in neuromonitoring during hypothermia therapy. $O$ : brain temperature, $\triangle$ : bladder temperature, $\bullet$ : brain and bladder temperature difference (delta T), $\square$ : cerebral perfusion pressure (CPP), $\Delta$ : jugular venous oxygen saturation $\left(\mathrm{SjO}_{2}\right)$.

at a depth of $2-3 \mathrm{~cm}$ from the brain surface. Many clinical studies have used intraventricular catheters for brain temperature measurement. Brain temperature is known to increase gradually, with a significant correlation with depth.6) The highest temperature is found in the lateral ventricle, which is $1.2^{\circ} \mathrm{C}$ higher than the intraparenchymal temperature. This difference between intraventricular and intraparenchymal temperatures may have caused the inverse findings for the temperatures of the brain and bladder in this study. Alternatively, this inversion of the brain and bladder temperatures may have resulted from ischemia induced by low CBF, decreased cerebral metabolic demand, or changes in hypothalamic regulation due to pharmacological treatment (sedation, paracetamol) during hypothermia. ${ }^{17)}$

This study found that the difference between brain and bladder temperatures in the SDH group was significantly lower than that in the DAI group, possibly because the brain temperature in the DAI group was increased by the higher cerebral metabolism and CBF induced by DAI. In addition, the brain temperature in the SDH group may have been influenced by environmental factors. Only intraparenchymal temperature fluctuated greatly after opening of the dura and during active cooling, whereas all other temperatures (jugular bulb, tympanic membrane, esophagus, bladder, pulmonary artery) remained at similar levels. ${ }^{5)}$ However, intraparenchymal brain temperature in a closed cranium remains constant, with no cooling effect from the environment. ${ }^{8)}$ Thus, brain temperature in an opened cranium may be influenced by environmental factors, and only brain temperature in a closed cranium will accurately reflect global brain temperature without environmental influences.

An animal study has shown that cerebral blood temperature changes are closely related to CPP. ${ }^{3)} \mathrm{A}$ decrease in cerebrovenous temperature would be induced by decreased CBF via reduced exchange of thermal energy from arterial blood to the cerebral component. Therefore, brain temperature is influenced by CBF. Some studies have looked at the differences between brain temperature and core temperature in a clinical setting, since the introduction of technology for direct measurement of brain temperature. ${ }^{5,12,17,20)}$ Brain temperature was much higher than rectal temperature if CPP was reduced to between 50 and $20 \mathrm{mmHg}$, indicating impaired CBF. ${ }^{13)}$ Furthermore, this difference decreased significantly as CPP was reduced to below $20 \mathrm{mmHg}$, indicating irreversible impairment of CBF. These findings may show that decreased arterial blood flow reduced "wash out" of the heat generated by brain metabolism with CPP between 50 and 20 $\mathrm{mmHg}$. With CPP under $20 \mathrm{mmHg}$, misery perfusion induced a decreased temperature gradient. However, our results indicated no relationship between delta T and CPP. In our study, CPP was kept above $70 \mathrm{mmHg}$ by therapeutic management. CBF will be influenced by factors other than CPP, so the changes in brain temperature observed in this study were not related to CPP.

Our $\mathrm{SjO}_{2}$ findings in patients with closed cranium showed a close relationship with delta T. $\mathrm{SjO}_{2}$ is an indicator of the balance between $\mathrm{CBF}$ and cerebral metabolism. As CBF exceeds the cerebral metabolic rate for oxygen, $\mathrm{SjO}_{2}$ also increases. Although we were unable to measure CBF in this study, the brain temperature and the difference between brain and core temperature are both largely dependent on CBF. ${ }^{17)}$ Therefore, the increased temperature difference reflects the higher $\mathrm{SjO}_{2}$ resulting from increased CBF. These findings suggest that measurement of brain temperature is a good indicator of 
CBF and cerebral metabolism, and can be used easily at the bedside. However, this relationship was not found in patients with decompressive craniectomy, since the brain temperature will be influenced by the environment in these patients. Furthermore, the physiological and pathophysiological conditions in SDH or contusional hematoma are not uniform spatially or chronologically. In contrast, since the conditions in DAI are uniform, both the brain temperature and $\mathrm{SjO}_{2}$ are good indicators of the condition of the whole brain.

The present study demonstrated that the mean delta $\mathrm{T}$ in the SDH group was significantly lower than that in the DAI group. Therefore, decompressive craniectomy influences the brain temperature through environmental factors. Furthermore, we found a close relationship between delta $\mathrm{T}$ and $\mathrm{SjO}_{2}$ in DAI patients with closed cranium. Measurement of brain temperature may be a reliable indicator of CBF and brain metabolism in DAI patients with closed cranium during hypothermia. However, only a small number of cases were examined in this study, and further experience is required to confirm these findings.

\section{References}

1) Busto R, Dietrich W, Globus MT, Valdes I, Scheinberg $\mathrm{P}$, Ginsberg $\mathrm{M}$ : Small differences in intraischemic brain temperature critically determine the extent of ischemic neuronal injury. J Cereb Blood Flow Metab 7: 729-738, 1987

2) Busto R, Globus MYT, Dietrich WD, Martinez E, Valdes I, Ginsberg MD: Effect of mild hypothermia on ischemia-induced release of neurotransmitters and free fatty acids in rat brain. Stroke 20: 904-910, 1989

3) Clausen T, Rieger A, Roth S, Soukup J, Furka I, Lindner J, Telgmaa L, Hennig C, Radke J, Menzel M: Cerebrovenous blood temperature-influence of cerebral perfusion pressure changes and hyperventilation. J Neurosurg Anesthesiol 12: 2-9, 2000

4) Clifton GL, Allen S, Barrodale P, Plenger P, Berry J, Koch S, Fletcher J, Hayes RL, Choi SC: A phase II study of moderate hypothermia in severe brain injury. J Neurotrauma 10: 263-271, 1993

5) Crowder CM, Tempelhoff R, Theard MA, Cheng MA, Todorov A, Dacey RG Jr: Jugular bulb temperature: comparison with brain surface and core temperatures in neurosurgical patients during mild hypothermia. J Neurosurg 85: 98-103, 1996

6) Hirashima Y, Takaba M, Endo S, Hayashi N, Yamashita K, Takaku A: Intracerebral temperature in patients with hydrocephalus of varying aetiology. $J$ Neurol Neurosurg Psychiatry 64: 792-794, 1998

7) Horrow JC, Rosenberg H: Does urinary catheter temperature reflect core temperature during cardiac surgery? Anesthesiology 69: 986-989, 1988

8) Lanier WL, Iaizzo PA, Murray MJ: The effects of convective cooling and rewarming on systemic and cen- tral nervous system physiology in isoflurane-anesthetized dogs. Resuscitation 23: 121-136, 1992

9) Lausberg G: [Central disorders of temperature regulation. Clinical-experimental study]. Acta Neurochir (Wien) 19: Suppl: 1-168, 1972 (German)

10) Marion DW, Obrist WD, Carlier PM, Penrod LE, Darby JM: The use of moderate therapeutic hypothermia for patients with severe head injuries: a preliminary report. J Neurosurg 79: 354-362, 1993

11) Mellergard P, Nordstrom CH: Epidural temperature and possible intracerebral temperature gradients in man. Br J Neurosurg 4: 31-38, 1990

12) Rossi S, Zanier E, Mauri I, Columbo A, Stocchetti N: Brain temperature, core temperature, and intracranial pressure in acute cerebral damage. J Neurol Neurosurg Psychiatry 71: 448-454, 2001

13) Rumana CS, Gopinath SP, Uzura M, Valadka AB, Robertson CS: Brain temperature exceeds systemic temperature in head-injured patients. Crit Care Med 26: 562-565, 1998

14) Sakamoto K, Fujisawa H, Koizumi H, Tsuchida E, Ito H, Sadamitsu D, Maekawa T: Effects of mild hypothermia on nitric oxide synthesis following contusion trauma in the rat. J Neurotrauma 14: 349-353, 1997

15) Shiozaki T, Sugimoto H, Taneda M, Yoshida H, Iwai A, Yoshioka T, Sugimoto T: Effect of mild hypothermia on uncontrollable intracranial hypertension after severe head injury. J Neurosurg 79: 363-368, 1993

16) Smith SL, Hall ED: Mild pre- and posttraumatic hypothermia attenuates blood-brain barrier damage following controlled cortical impact injury in the rat. J Neurotrauma 13: 1-9, 1996

17) Soukup J, Zauner A, Doppenberg EM, Menzel M, Gilman C, Young HF, Bullock R: The importance of brain temperature in patients after severe head injury: Relationship to intracranial pressure, cerebral perfusion pressure, cerebral blood flow, and outcome. J Neurotrauma 19: 559-571, 2002

18) Stone JG, Young WL, Smith CR, Solomon RA, Wald A, Ostapkovich N, Shrebnick DB: Do standard monitoring sites reflect true brain temperature when profound hypothermia is rapidly induced and reversed? Anesthesiology 82: 344-351, 1995

19) Suehiro E, Fujisawa H, Ito H, Ishikawa T, Maekawa T: Brain temperature modifies glutamate neurotoxicity in vivo. J Neurotrauma 16: 285-297, 1999

20) Verlooy J, Heytens L, Veeckmans G, Selosse P: Intracerebral temperature monitoring in severely head injured patients. Acta Neurochir (Wien) 134: 76-78, 1995

21) Yamakami I, Yamaura A: Effects of decompressive craniectomy on regional cerebral blood flow in severe head trauma patients. Neurol Med Chir (Tokyo) 33: 616-620, 1993

Address reprint requests to: Eiichi Suehiro, MD, PhD, Department of Neurosurgery, Kenwakai Ohtemachi Hospital, 15-1 Ohte-machi, Kokurakita-ku, Kitakyushu, Fukuoka 803-8543, Japan.

e-mail: suehiro-nsu@umin.ac.jp 